\title{
IL-6 Mediates 11ßHSD Type 2 to Effect Progression of the Mycobacterial Cord Factor Trehalose 6,6'-Dimycolate-Induced Granulomatous Response
}

\author{
April N. Abbott ${ }^{a}$ Kerry J. Welsh ${ }^{d, e}$ Shen-An Hwang ${ }^{c, d}$ Paulina Płoszaj $^{f}$ \\ Tina Choudhury ${ }^{d}$ Sydney Boyd ${ }^{d}$ Michael R. Blackburn ${ }^{b}$, e \\ Robert L. Hunter, Jr. ${ }^{c-e}$ Jeffrey K. Actor ${ }^{c-e}$ \\ ${ }^{a}$ Department of Laboratory Medicine, University of Washington, Seattle, Wash., Departments of \\ ${ }^{b}$ Biochemistry and Molecular Biology and ${ }^{\mathrm{C} P a t h o l o g y}$, ${ }^{\mathrm{M}}$ Medical School, University of Texas-Houston and \\ e Graduate School of Biomedical Sciences, University of Texas-Houston Health Science Center, Houston, Tex., USA; \\ fWroclaw Medical University, Wroclaw, Poland
}

\section{Key Words}

Mycobacterial glycolipid $\cdot$ Granuloma $\cdot$ Inflammation •

Lung $\cdot 11 \beta$-hydroxysteroid dehydrogenase

\begin{abstract}
Granulomatous structures are highly dynamic during active mycobacterial infection, with accompanying responsive inflammation contributing to modulation of pathology throughout the course of disease. The heightened inflammatory response coinciding with initiation and maintenance of newly developing granulomatous structures must be limited to avoid excessive damage to bystander tissue. Modulating the cellular bioavailability of glucocorticoids by local regulation of $11 \beta \mathrm{HSD}$ enzymes within responding tissue and parenchyma would allow controlled inflammatory response during infection. Mycobacterial glycolipid trehalose 6,6'dimycolate was used to induce strong pulmonary granulomatous inflammation immunopathology. Pulmonary corticosterone was significantly increased at days 3 and 5 after administration. An inverse relationship of $11 \beta \mathrm{HSD} 1$ and $11 \beta \mathrm{HSD} 2$ message correlated with pathology development. Immunohistochemical analysis also demonstrated that $11 \beta H S D 2$ is expressed in proximity to granulomatous le-
\end{abstract}

sions. A role for pro-inflammatory IL-6 cytokine in regulation of converting enzymes to control the granulomatous response was confirmed using gene-disrupted IL-6-/- mice. A model is proposed linking IL-6 to endocrine-derived factors which allows modification of active corticosterone into inert 11-dehydrocorticosterone at the site of granuloma formation to limit excessive parenchymal damage.

Copyright $\odot 2011$ S. Karger AG, Basel

\section{Introduction}

Nearly one third of the world's population harbors Mycobacterium tuberculosis, the causative agent of tuberculosis (TB), with an estimated 9.4 million new cases of TB reported by the World Health Organization in 2008 [1]. The disease represents a tremendous global burden, with continuing major economic impact despite therapeutic intervention [2]. Much effort in the biomedical sciences is specifically targeted towards increased under-

This work was supported by NIH grant 1R21AI058247-1.

\section{KARGER}

๑ 2011 S. Karger AG, Basel

Fax +41613061234 E-Mail karger@karger.ch www.karger.com www.karger.com/nim
Jeffrey K. Actor, $\mathrm{PhD}$

Department of Pathology and Laboratory Medicine, MSB 2.214

University of Texas-Houston Medical School

6431 Fannin, Houston, TX 77030 (USA)

Tel. +1 713500 5344, E-Mail Jeffrey.K.Actor@uth.tmc.edu 
standing of immune mechanisms that contribute to the development of this disease. This is especially true relative to manifestation of the granulomatous response, which is considered the pathological hallmark of TB infection. Upon encountering the bacilli, the host responds by initiating a protective granulomatous immune structure critical for host survival, impairment of which results in rapid mycobacterial dissemination $[3,4]$ and worsened disease $[5,6]$. Within the past few years, the 'tubercle' has shed the simple image of serving as a barrier between organism and host, and is now recognized as a complex and dynamic immunological structure [7, 8]. Addressing how a microenvironment develops to allow the host to isolate and contain the organism is an area of active interest.

An ever-increasing body of evidence suggests that modulation of the inflammatory response is, in part, under neuroendocrine control. The hypothalamic-pituitary-adrenal (HPA) axis is activated upon infectious assault, and more specifically, subsequently produced proinflammatory mediators $[9,10]$. There now appears to be a clear effect related to pathogenesis during mycobacterial infection [11-13]. HPA activation initiates release of biologically active glucocorticoids (GCs; cortisol in humans and corticosterone in rodents) into the bloodstream which function to dampen further inflammatory mediator production. This is accomplished by inhibiting proinflammatory transcription factors [14] and limiting cellular immunity directed by recruited lymphocytes [9]. This neuroendocrine response is hypothesized to aid in modulating, but not completely halting the inflammatory immune response. As early events in TB-induced granuloma development are contingent upon a strong pro-inflammatory response, specifically the induction of TNF- $\alpha$ and IL- 6 [4, 15-18], one could surmise that the GC regulatory principles defined in other acute infectious processes also govern progression of $M$. tuberculosis infection and ensuing pathology [19]. A large body of work is dedicated to deciphering the role of GCs in mycobacterial infections, however, the majority of studies focus only on the breakdown of host protection (that is, the Th1 to Th2 shift) during active or re-active disease states $[20,21]$, or on alteration of GC receptors in affected tissues [22].

Mycobacterial glycolipid trehalose 6,6'-dimycolate (TDM; cord factor) is used experimentally to induce strong pulmonary granulomatous inflammation that recapitulates $M$. tuberculosis-induced pulmonary immunopathology without need for persistent infectious stimuli $[23,24]$. The response elicited by TDM makes it a par- ticularly useful tool for study of early events during the initiation and maintenance phases of granuloma development $[16,25]$. Previous studies utilizing both the TDM model and murine $M$. tuberculosis infection provided evidence that serum GC levels can change during acute granulomatous responses [20,26-28]. Although circulating GCs are almost exclusively under HPA axis control, it is the intratissue GC concentration which ultimately dictates anti-inflammatory function to mediate tissue damage. These tissue-specific GCs are tightly modulated by $11 \beta$-hydroxysteroid dehydrogenase (11ßHSD) enzymes [29]. Specifically, the physiological role of $11 \beta \mathrm{HSD}$ type 2 (11ßHSD2) is to convert active corticosterone (cortisol) into inert 11-dehydrocorticosterone (cortisone); whereas the inverse reaction is carried out by $11 \beta \mathrm{HSD}$ type 1 (11ßHSD1). More recent findings indicate that in response to TDM, pulmonary corticosterone levels are altered in a pattern that is independent of serum concentrations [30], suggesting that modulation of active GC moieties occurs directly within the lung itself. We hypothesize that induction of $11 \beta \mathrm{HSD} 2$ during granuloma development would convert corticosterone to the inert derivative, thus limiting corticosterone availability to GC receptors. If this occurs during a concurrent reduction or stabilization in 11ßHSD1 enzymatic activity, the result would be a limitation to physiological GC, thus further restricting GC-derived effects.

The studies presented here provide evidence that an enzymatically controlled mechanism may directly influence the early integrity of the granulomatous structure and impact pathological progression. Specifically, examination of early TDM-induced events addresses the potential of the site-specific corticosterone-controlling enzymes, $11 \beta H S D$ s, to manage granuloma development. Furthermore, the role of IL- 6 in this response is addressed, as a mediator of enzymes that control corticosterone activity, which ultimately affects pathology due to triggered pro-inflammatory responses.

\section{Materials and Methods}

Mice

Female C57BL/6 mice and gene-disrupted IL-6-/- mice (B6.129S2-Il6tm1Kopf/J) were obtained from Jackson Laboratories (Bar Harbor, Me., USA). Mice were housed in microisolater cages in groups of 4 , given food and water ad libitum, and allowed to acclimate to housing environment for 1 week prior to experimentation. Mice were 6-9 weeks of age at initiation of experiments. All animal work was conducted under the approval of the University of Texas Health Science Center (UTHSC) animal welfare committee (document No. AWC-07-093). 


\section{Emulsion Preparation and Administration}

A TDM (Sigma, St. Louis, Mo., USA) water-in-oil emulsion was prepared as previously described [16]. Briefly, lyophilized TDM was reconstituted in hexane-ethanol (9:1 v/v) and $25 \mu \mathrm{g}$ of TDM per mouse was dried down under air. The TDM was homogenized in $1 \mu \mathrm{l}$ of Drakeol oil (Penreco, Indianapolis, Ind., USA) using a glass tube and Teflon pestle. Finally, $49 \mu \mathrm{l}$ of PBS (Mediatech, Herndon, Va., USA) containing $0.2 \%$ Tween 80 (Mallinckrodt, Hazelwood, Mo., USA) was admixed to create a stable emulsion. Fifty microliters of the emulsion was injected intravenously into the tail of each mouse. A control emulsion, containing only water and oil, was prepared and administered alongside the TDM emulsion.

\section{Specimen Collection and Processing}

All collections took place between 7:30 and 9:30 a.m. to control for diurnal corticosterone fluctuations. Animals were bled per retro-orbital venipuncture and sacrificed by cervical dislocation on days 3, 5 and 7 after emulsion administration. Naïve animals and animals sacrificed 3 days after administration of emulsion only (no TDM) served as controls for analysis. Serum was obtained by centrifuging whole blood in microtainer serum separator tubes (BD, Franklin Lakes, N.J., USA). Prior to collection, lungs were perfused with PBS containing $1 \mathrm{~mm}$ EDTA (GIBCOBRL, Grand Island, N.Y., USA). Lung, liver, spleen, kidneys and adrenal glands were aseptically removed, processed and weighed. The lung, liver and spleen of each animal were sectioned into four pieces, one each for histology, RNA analysis, corticosterone measurement and protein analysis. The kidneys and adrenal glands from each mouse were not sectioned, but rather allocated for use. Tissues for protein analysis were immediately homogenized in microcentrifuge tubes with a plastic pestle and incubated in supplemented Dulbecco's modified Eagle's medium (DMEM) as previously described [31]. Following initial processing, all specimens, except those for histology and supernatants for protein measurement, were frozen at $-80^{\circ} \mathrm{C}$ for future analysis.

Tissues for histology were placed in $10 \%$ buffered formalin (Fisher Scientific, Pittsburg, Pa., USA) and allowed to fix overnight. Processing of the specimens was performed by the UTHSC Histology Laboratory. Per standard protocol, tissues were embedded in paraffin blocks and 5 - $\mu$ m-thick sections were prepared and stained with hematoxylin (Surgipath, Richmond, Ill., USA) and eosin (Richard-Allen Scientific, Kalamazoo, Mich., USA). Immunohistochemical examination of $11 \beta \mathrm{HSD} 2$ expression was carried out using sheep-derived polyclonal antibodies against 11ßHSD2 (AB1296; Millipore, Bellerica, Mass., USA) diluted to a concentration of 1:3,000 in sheep serum. The Vectastain ABC method (Vector Laboratories, Burlingame, Calif., USA) allowed for visualization of $11 \beta H S D 2$ per manufacturer's protocol [32]. The sections were then counterstained with hematoxylin, dehydrated, and a coverslip was affixed.

\section{Isolation and Purification of $m R N A$, Reverse Transcription and Quantitative PCR}

For RNA analysis, tissue was homogenized in RNA-Bee (TelTest Inc., Friendswood, Tex., USA) using plastic pestles and total RNA was isolated using phenol-chloroform extraction methods per manufacturer's instructions. Two micrograms of RNA was reverse transcribed and amplification of cDNA was assessed by the Taqman assay, using an ABI PRISM 7700 Sequence Detection
System (Applied Biosystems, Foster City, Calif., USA) per previously published methods and sequences $[16,33]$. Changes in gene expression for 11ßHSD1 and 11ßHSD2 were analyzed by using the $-2^{\Delta \Delta C T}$ method as described [34], with $\beta$-actin used for normalization of samples. Data are displayed as fold change in mRNA, where each treatment group is compared to naïve animals.

\section{Corticosterone Evaluation}

Serum and tissue corticosterone levels were quantified using competitive Corticosterone HS EIA kits (Immunodiagnostic Systems Inc., Fountain Hills, Ariz., USA). Serum samples were directly utilized per manufacturer's instruction; however, tissue specimens underwent a corticosterone extraction procedure prior to analysis. Briefly, an ice-cold methanol (Sigma) and deionized water $(7: 2 \mathrm{v} / \mathrm{v})$ solution was added and snap-frozen tissue was disrupted using a PRO200 homogenizer. The homogenate was shaken at room temperature for $30 \mathrm{~min}$ and then centrifuged for 10 min at 13,000 rpm. A Speedvac was used to evaporate the solvent from half a milliliter of the supernatant. The resultant corticosterone residue was dissolved in $200 \mu \mathrm{l}$ calibrator diluent and underwent sample preparation and analysis as outlined by the manufacturer.

\section{ELISA Analysis of Pro-Inflammatory Mediators}

Levels of IL-1 $\beta$, IL- 6 , TNF- $\alpha$ and IL-12p40 were measured by a sandwich ELISA according to the manufacturer's instructions (R\&D Systems), as previously described [16, 30, 35]. Briefly, capture antibody-coated Costar 96-well plates (Corning, Corning, N.Y., USA) were washed (0.5\% Tween-20 in PBS) and blocked (1\% BSA, $5 \%$ sucrose, $0.05 \% \mathrm{NaN}_{3}$ in PBS). Supernatants were incubated for $2 \mathrm{~h}$, followed by detection using biotin-conjugated secondary antibodies, with visualization using streptavidin-horseradish peroxidase $(\mathrm{R} \& \mathrm{D})$ and TMB Microwell peroxidase substrate (KPL, Gaithersburg, Md., USA). Reactions were halted using $1 \mathrm{M} \mathrm{H}_{2} \mathrm{SO}_{4}$, and the absorbance was read at 570 and $450 \mathrm{~nm}$ on an ELISA plate reader (Molecular Devices, Sunnyvale, Calif., USA). The mean of duplicate wells was calculated based on a standard curve generated for each assay using manufacturer-supplied recombinant molecules $(\mathrm{R} \& \mathrm{D})$ ). The lower limit for detection was $15-32 \mathrm{pg} / \mathrm{ml}$.

\section{IL-6 Regulation of 11ßHSD from Lungs or Cultured Cells}

Lungs from naïve wild-type C57BL/6J mice were aseptically removed and homogenized per the ELISA protocol. Homogenates in DMEM were pooled and divided such that each set of lungs resulted in 3 replicates. Samples were spiked with either 1 or $5 \mathrm{ng}$ of recombinant IL- 6 or TNF- $\alpha$. These concentrations were established based on ELISA data, indicating that the lower dose (1 ng) best approximates endogenous levels found in the lung during the course of TDM treatment while the higher dose is typically seen during exacerbated inflammatory responses. Following cytokine treatment, homogenates were incubated at $37^{\circ} \mathrm{C}$ under $5 \% \mathrm{CO}_{2}$ for $10 \mathrm{~h}$. Samples were centrifuged at $1,000 \mathrm{rpm}$ for $10 \mathrm{~min}$ and RNA Bee was added to the cellular pellets for RT-PCR analysis of $11 \beta H S D$ enzymes. All samples were stored at $-20^{\circ} \mathrm{C}$ until analysis. Bone marrow-derived macrophages (BMM), murine alveolar macrophages (MHS; ATCC, Manassas, Va., USA) and murine epithelial type II cells (MLE-15; ATCC) were treated with IL-6 to determine the specific cell type making $11 \beta$ HSD enzymes. BMM 
were isolated as previously described [36]. Briefly, C57BL/6J mice were sacrificed by cervical dislocation and lower limbs were removed. Bone marrow-derived cells were flushed from femurs using DMEM without FBS. Cells were pooled, washed with PBS, reconstituted in McCoy's media containing 10\% FBS, $100 \mu \mathrm{g} / \mathrm{ml}$ penicillin G (Sigma) and $50 \mu \mathrm{g} / \mathrm{ml}$ gentamicin (Sigma), and counted. Recombinant GM-CSF (Cell Sciences, Canton, Mass., USA) at $10 \mathrm{ng} / \mathrm{ml}$ was added and a concentration of $1 \times 10^{6}$ cells was plated per well of a 24 -well culture plate. Cells underwent differentiation for 3 days at $37^{\circ} \mathrm{C}$ at $5 \% \mathrm{CO}_{2}$, at which time media was removed and fresh media was added. Differentiation and expansion continued an additional 3 days to achieve a nearly confluent and adherent macrophage population. Media was removed, cells were washed with PBS, and rested for 1 day in DMEM containing $5 \%$ FBS. The following day, recombinant IL- 6 or TNF- $\alpha$ ( 1 or $5 \mathrm{ng}$ ) was administered and cells were incubated for $8 \mathrm{~h}$. TDM was added as described, and compared to BSA-coated bead controls $[36,37]$. Supernatants were removed, RNA Bee was added, and plates were placed at $-20^{\circ} \mathrm{C}$ for future mRNA isolation and analysis. MHS and MLE-15 cells were cultured in RPMI-1640 (Sigma) containing $5 \%$ FBS as recommended by ATCC. Nonadherent cells were removed and fresh media was added prior to cytokine treatment as outlined above.

\section{Statistical Analysis}

Data are presented as the means $\pm 1 \mathrm{SD}$. Normally distributed data were analyzed using GraphPad Prism 4 software (La Jolla, Calif., USA) by an unpaired t test where the difference between two means was compared within groups. Two-way ANOVA was used for statistical analysis between strains for results of in vivo experimentation. Differences between means were considered significant at a level of $\mathrm{p}<0.05$.

\section{Results}

\section{IL-6-Deficient Mice Fail to Maintain TDM-Induced Granulomatous Response}

As previously reported [16], IL-6-deficient mice demonstrated inability to localize inflammation after administration of mycobacterial TDM compared to control challenged mice. Wild-type C57BL/6 mice formed cohesive and transient granulomas after a single intravenous injection of TDM (fig. 1). Focal histiocytic clusters comprised primarily of monocytes were evident at 3 days after TDM administration and grew in size and complexity through day 7. In contrast, the IL-6-deficient mice demonstrated acute inflammation indicative of failed granuloma maintenance. Initiation of granulomatous response was evident in these knockout mice by day 3, with focal infiltration of monocytic cells. However, there was a failure to contain inflammation. By 7 days after challenge, acute inflammation was increased with evidence of early edema and alveolar cell-wall thickening, as well as lymphocytic cuffing around occluded vesicles.

IL-6 Mediates 11ßHSD Type 2 Affecting

Granuloma Development

\section{Altered Pro-Inflammatory Cytokine Protein Profiles}

in IL-6-Deficient Mice after TDM Challenge

Cytokine protein patterns were examined in the lungs of mice challenged with TDM (fig. 2). Responses were similar to those previously reported [16]. Challenged wildtype and IL-6-deficient mice had significantly elevated levels $(p<0.05)$ of IL-1 $\beta$, TNF- $\alpha$ and IL-12p40 on both days 3 and 7 in comparison to noninjected mice, with significant elevation for all cytokines examined at the earlier time point. While the IL-6-deficient mice demonstrated a general trend toward relatively reduced pro-inflammatory response compared to the parental controls, only IL$1 \beta$ was significantly decreased at day 3 after injection. When IL- 6 was examined, the parental control mice made significant quantities of IL- 6 at both days 3 and 7 after injection. The deficient mice, as expected, were not able to produce IL- 6 in response to the administered TDM.

\section{Increased Corticosterone in Lungs of TDM-Challenged} Mice

To understand the role of GCs in this process, active corticosterone was initially evaluated in tissue and serum from wild-type C57BL/6 mice administered TDM. Of the tissues examined, pulmonary (the site of pathology) and kidney levels of corticosterone were most significantly affected, with significant increases at days 3 and 5 in the lung, and at 3, 5 and 7 days in the kidney $(\mathrm{p}<0.05)$ (fig. 3). Serum corticosterone was relatively stable, with no significant change at any time point relative to untreated mice or controls treated with oil emulsion alone. In a separate experiment, corticosterone measurement was extended to evaluate levels in the lung and serum of the knockout mice (fig. 4). There was no difference between levels found in the lung or serum of samples obtained from TDM-treated IL-6-deficient mice compared with those of parental control animals.

\section{Inverse Relationship of $11 \beta H S D 1$ and $11 \beta H S D 2$ \\ Message Correlates with Pathology}

Further analysis was undertaken to examine the $11 \beta H S D 1$ and $11 \beta H S D 2$ enzymes that enhance biologically active 11-hydroxy steroid and inert 11-keto steroid levels, respectively (fig. 5) [38]. Quantitative analysis of mRNA for $11 \beta H S D 1$ revealed a significant drop in lung message after TDM administration in wild-type controls, and levels remained low throughout the course of experimentation. Diminished levels were also seen in the liver, but not in other tissues. In concert with the changes in $11 \beta H S D 1$, levels for $11 \beta H S D 2$ were markedly elevated in the lung, and to an extent also elevated in the liver at 


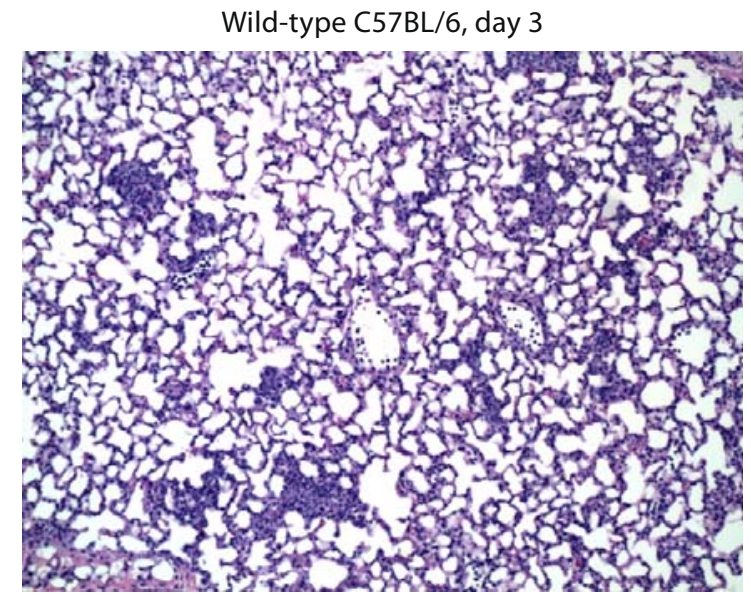

IL-6 KO, day 3

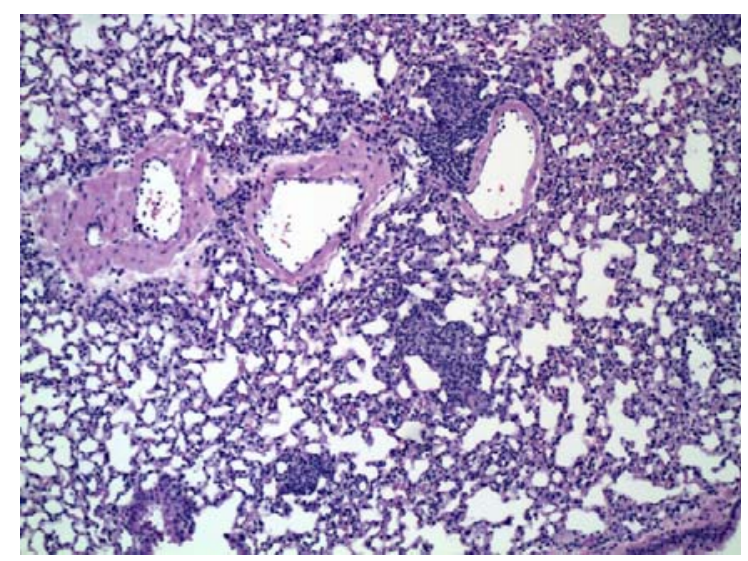

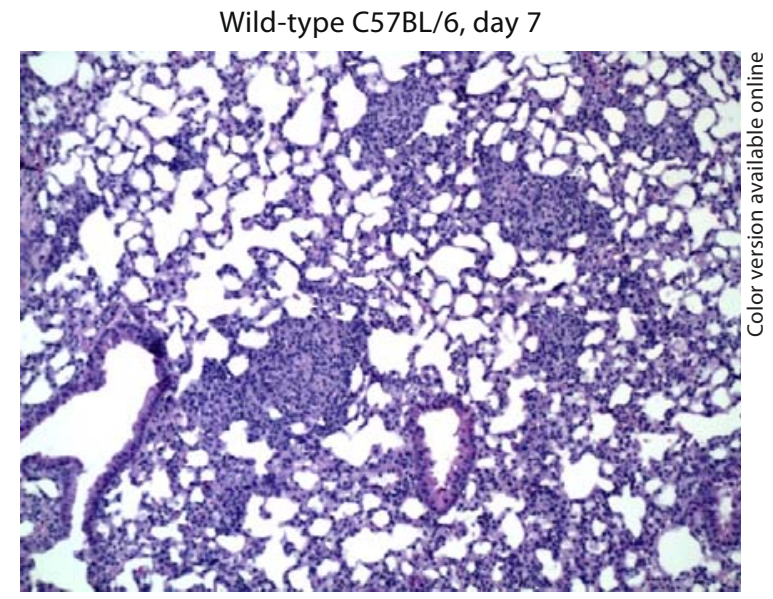

IL-6 KO, day 7

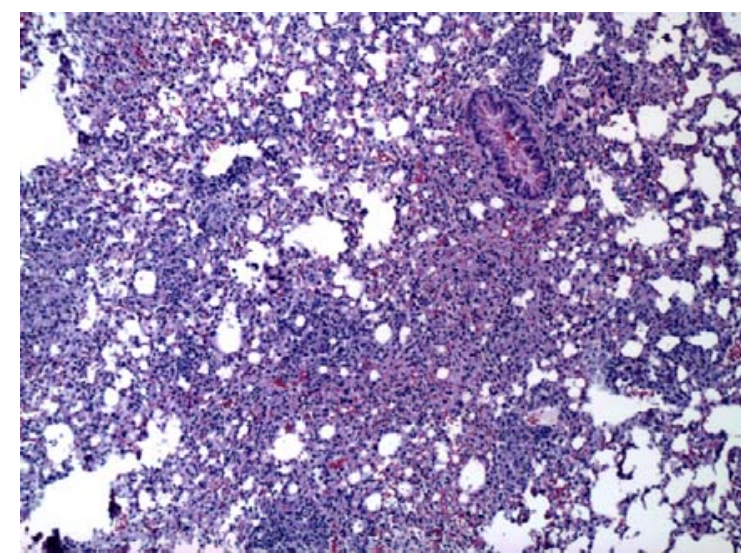

Fig. 1. Pulmonary histology showing pathological development following TDM administration. TDM was administered intravenously and mice were sacrificed at days 3 and 7 after injection. Histologic examination of lungs revealed acute granulomatous response, increasing through day 7 after TDM injection, culminating in marked monocytic infiltration and increased cellular aggregation. IL-6-deficient mice revealed monocytic infiltrates at day 3 , but were unable to maintain cohesive granulomatous response through day 7. Administration of oil emulsion control (without TDM) revealed no inflammation at comparative days, as previously reported $[16,31]$. Hematoxylin and eosin, $\times 100$. the later time point. In contrast, the message for 11ßHSD1 in adrenals was considerably elevated, perhaps allowing for increased active production of corticosterone in that tissue; however, the 11ßHSD2 mRNA was not significantly altered.

Relationships between the $11 \beta \mathrm{HSD} 1$ and $11 \beta \mathrm{HSD} 2$ messages were further examined in the lungs of the IL-6deficient mice. Of interest, the relative relationship between messages was reversed in the deficient mice, with marked and significant decrease in $11 \beta H S D 1$ over the course of experimentation ( $\mathrm{p}<0.05$ ) (fig. 6). In the IL-6deficient mice, the mRNA for 11ßHSD2 was unchanged over time, indicating a loss of regulation in the absence of IL-6.

\section{Lack of 11ßHSD2 in Lungs of IL-6-Deficient Mice} after TDM Administration

Lung sections from wild-type C57BL/6 and IL-6-deficient mice were stained with antibodies against $11 \beta H S D 2$ at days 5 and 7 after TDM administration to visualize enzyme location and distribution relative to active development of histopathology (fig. 7). Protein was readily apparent by day 5 in the wild-type mice, with strong punctuate staining in and around the granuloma. The presence of $11 \beta \mathrm{HSD} 2$ was still readily visible at day 7, with steady accumulation within the expanding manifestation of pathology. In contrast, there was markedly reduced $11 \beta \mathrm{HSD} 2$ present in the lungs of IL-6-deficient mice, with only scattered positive cells at day 5 
Fig. 2. TDM cytokine protein patterns in the lungs of TDM-challenged mice. Wildtype (open bars) and IL-6-deficient mice (solid bars) were examined for changes in IL-1 $\beta$, TNF- $\alpha$, IL- 6 and IL-12p40 protein produced on days 3 and 7 after TDM administration. The IL-6-deficient mice demonstrated a general trend toward relatively reduced proinflammatory response compared to the parental controls, however, IL-1 $\beta$ was the only marker significantly decreased at day 3 after injection. Responses were consistent with previously reported levels [16]. $\mathrm{n}=4$; $^{*} \mathrm{p}<0.05$.

Fig. 3. Tissue-specific corticosterone modulation reveals unique pattern at the site of inflammation. Pulmonary corticosterone was elevated at days 3 and 5 following TDM administration, but at day 7 , corticosterone was not significantly elevated above naïve or emulsion-only (oil) treated animals. This pattern is unique when compared to other tissues (kidney, liver, spleen, adrenal) and circulating (serum) levels. This decrease in pulmonary corticosterone at day 7 , when compared to earlier time points, coincides with development of classic granulomatous structures. Overall, corticosterone was elevated in the lung and kidney, but no significant changes were observed in the serum, spleen, or adrenal gland. $\mathrm{n}=4$; $^{*} \mathrm{p}<0.05$.
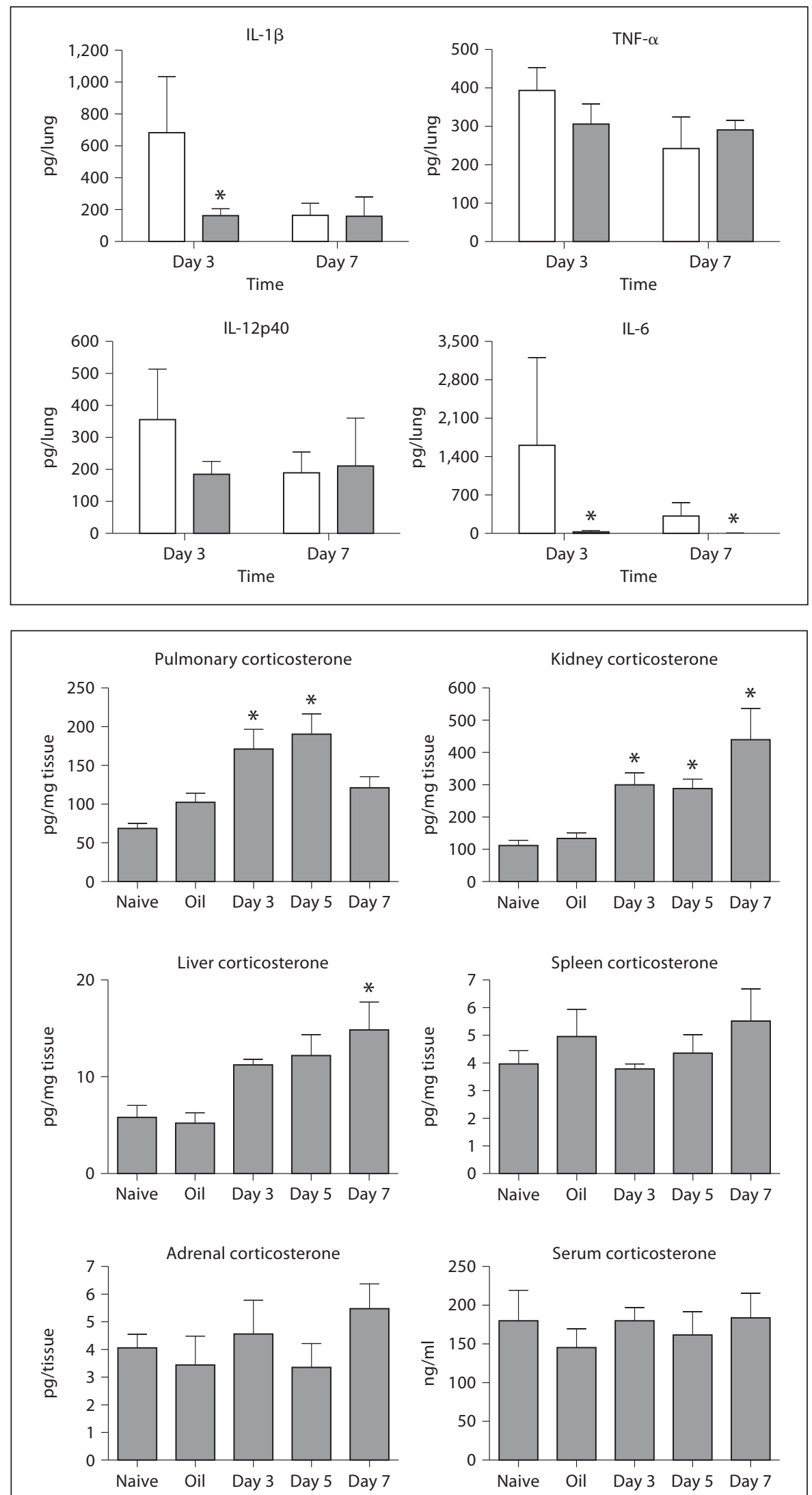


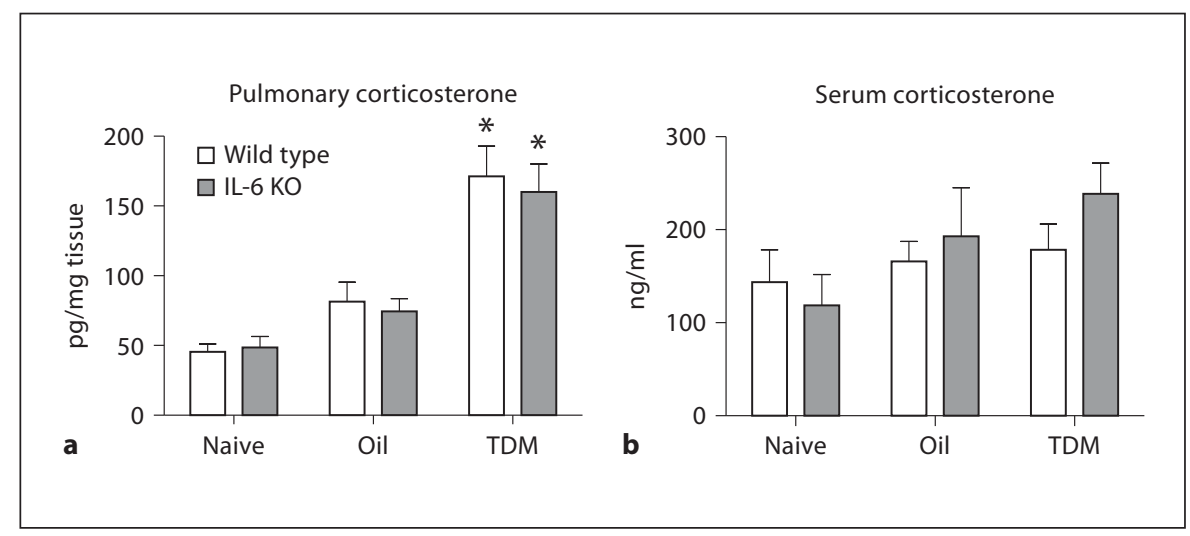

Fig. 4. Corticosterone levels were comparable between IL-6-sufficient and-deficient mice. Pulmonary (a) and serum (b) corticosterone levels were measured at day 5 by EIA for naïve, oil, and TDM-treated C57BL/6J mice. No significant difference in corticosterone levels was detected between wild type (open bars) and IL-6-deficient mice (solid bars) during this experiment. No sig- nificant elevation in corticosterone was observed in the serum of either group when TDM or emulsion alone (oil) was administered. Mice given TDM had increased levels of pulmonary corticosterone when compared to naïve animals, regardless of IL-6 status. $\mathrm{n}=3-6$ mice per group; ${ }^{*} \mathrm{p}<0.05$ when both groups were compared to naïve mice. after TDM administration. By day 7, there was virtually no specific staining above background in fields of representative altered pathology. No enzyme-specific staining was apparent in the untreated or oil emulsion-treated controls, indicating lack of significant quantities of constitutive 11ßHSD2 expression within lung parenchyma.

\section{IL-6 Induces Production of 11ßHSD2 from Normal Lung Tissue}

The relationship of IL- 6 as a regulator for expression of the $11 \beta H S D 1$ and $11 \beta H S D 2$ enzymes was further addressed. Naïve lungs obtained from wild-type mice were isolated and minced (fig. 8). IL-6 was added in vitro to lung suspensions, and message isolated after incubation. Addition of IL- 6 at 1 or $5 \mathrm{ng} / \mathrm{ml}$ led to increased mRNA expression of $11 \beta H S D 2$, but not $11 \beta H S D 1$. This was specific for IL-6; the pro-inflammatory mediator TNF- $\alpha$ did not induce expression of either enzyme at $1 \mathrm{ng} / \mathrm{ml}$ and only slightly increased $11 \beta H S D 2$ at the higher dose treatment. An attempt was made to determine the cell phenotype responsible for production of the $11 \beta \mathrm{HSD} 2$ message (fig. 9). However, addition of IL-6 to isolated epithelial cells (MLE15), alveolar macrophages (MHS) or BMM was not sufficient in and of itself to induce change in message. This implicates either a different cell phenotype for message production or a requirement for additional factors to induce changes in 11ßHSD2 mRNA from those cell phenotypes.

\section{Discussion}

The neuroendocrine immune response is intricately regulated during development and maintenance of granulomatous inflammation. Evidence exists that GCs play a critical role during granuloma formation, particularly during mycobacterial infection $[39,40]$. Early studies focused on changes in GC receptor expression as a potential regulator of host resistance or susceptibility to tissue damage [22]. Since then, it has become clear that GC regulation in the host can modify the development of protective adaptive $T$ cell function that contributes to maintenance of pathology after the infection has become established [20,41]. But to date, no research laboratory has investigated the initiating pro-inflammatory events with activity of the GC mediators to mediate early pathological development. The model of TDM-induced granulomatous response presented here allows identification of factors which affect functional GC activity. Furthermore, findings implicate a role for pro-inflammatory IL- $6 \mathrm{cy}-$ tokine in regulation of converting enzymes to control this response.

Granulomatous structures are highly dynamic, especially during active infection $[5,42]$. Histological studies in mice indicate that tissue inflammation continues for several months after aerosolized $M$. tuberculosis infection $[43,44]$. The heightened inflammatory response occurring as the granulomatous structure takes shape must be reined in to avoid potential tissue damage. Modulating 
Fig. 5. Enzyme regulation of the lung, but no other organ, supports corticosterone depletion. Pulmonary 11ßHSD1 mRNA (left panels) was dramatically lower (4fold) following TDM administration. The type 1 enzyme was not decreased in any other tissue (liver, spleen, kidney, or adrenal). Pulmonary 11ßHSD2 mRNA (right panels) was significantly elevated (3-fold) following TDM treatment. The liver was the only other organ in which increased type 2 enzyme was present, and this was not until day 7. Importantly, the lung was the only tissue with cooperative regulation of both enzymes that supports corticosterone metabolism. $\mathrm{n}=4{ }^{*} \mathrm{p}<0.05$.
Pulmonary $11 \beta \mathrm{HSD} 1$

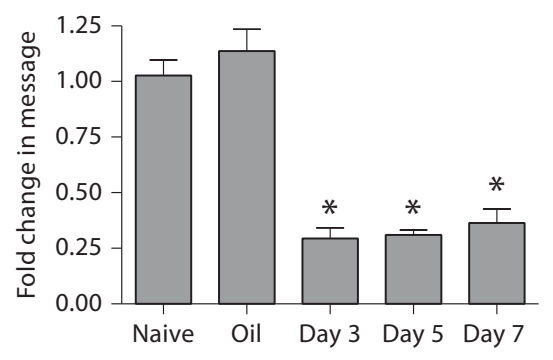

Pulmonary $11 \beta \mathrm{HSD} 2$
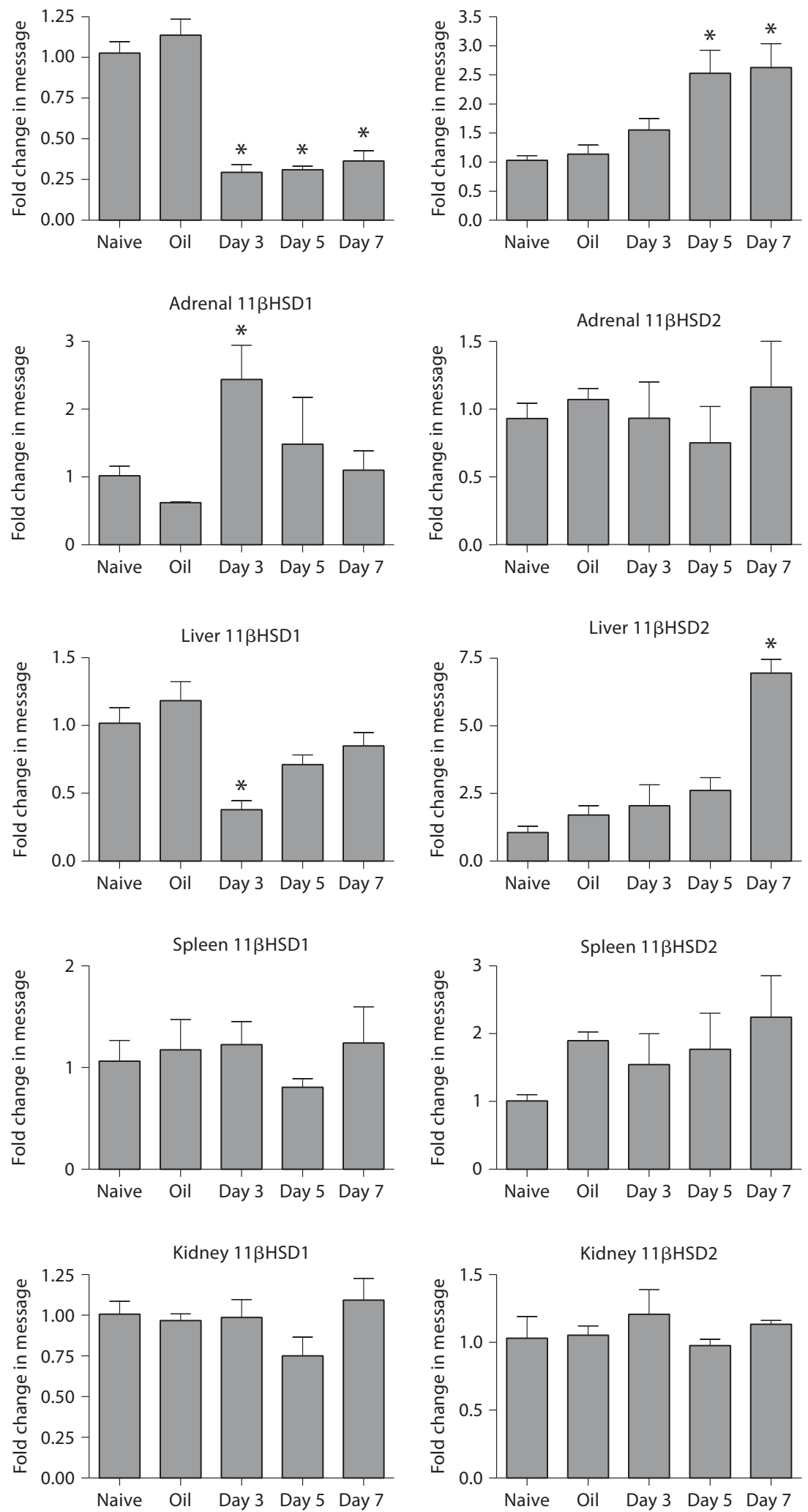


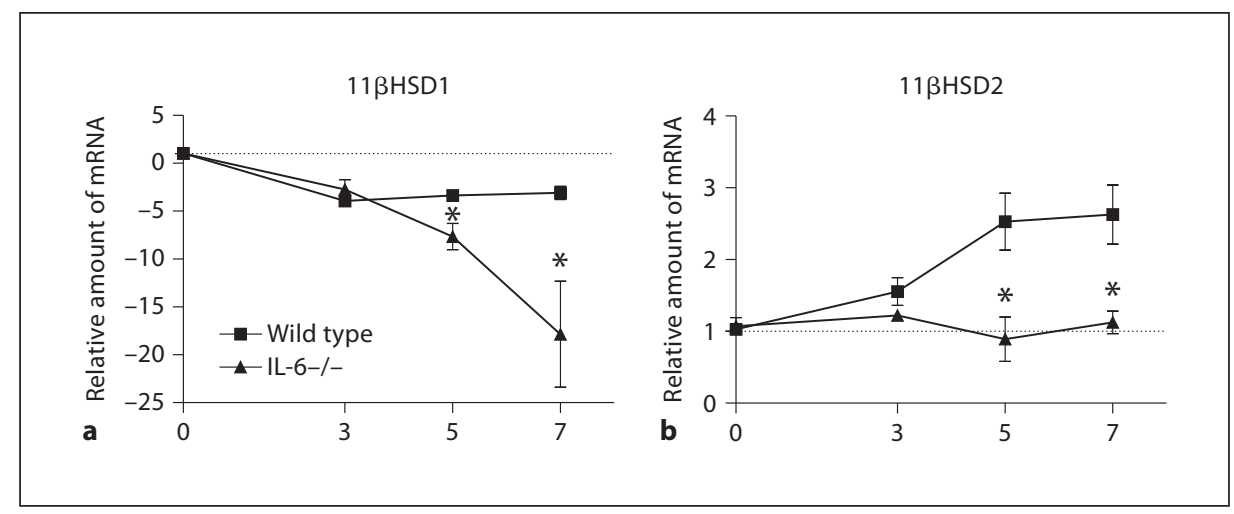

Fig. 6. Corticosterone-regulating enzymes unchanged in IL-6-/mice. a Wild-type mice have a significant decrease in 11ßHSD1 mRNA (approximately 4-fold) at days 3, 5 and 7 after TDM administration. IL-6-/- mice have an even more significant decrease (18-fold) in type 1 enzyme message over time. b Wild-type mice have increasing $11 \beta$ HSD2 message in the lungs after TDM treatment. Specifically, levels are significantly elevated at days 5 and 7 (approximately 3 -fold that observed in naïve animals). No change in the level of $11 \beta$ HSD2 was detected over time in the IL6-/- mice. Significant differences between groups at each time point were noted. Dotted line represents fold change (set at 1 ) for naïve mRNA levels. $\mathrm{n}=3-8$ mice per group; ${ }^{*} \mathrm{p}<0.05$ when compared between groups at the same time point. the cellular bioavailability of GCs reaching the granuloma could account for the sustained but controlled inflammatory response observed during acute $M$. tuberculosis infection. The hypothesis is that during active granuloma formation, local regulation of $11 \beta \mathrm{HSD}$ enzyme production serves as a mechanism to limit active GC availability, thereby promoting a continuous, yet controlled, pro-inflammatory microenvironment (fig. 10). This is supported by immunohistochemical evidence demonstrating that $11 \beta \mathrm{HSD} 2$ is expressed in proximity to the TDM-induced granulomatous lesions in our model system.

The ability to mount and sustain a mycobacterial-induced granulomatous response is severely compromised by IL- 6 deficiency. IL- 6 deficiency contributes to aberrant cellular recruitment and migration, leading to deleterious pathological outcomes for the host $[18,45]$. As a model system, mycobacterial TDM can induce granulomas which mimic many of the early pro-inflammatory events occurring during challenge with the infectious agent. Administration of TDM initiates local production of pro-inflammatory cytokines in the lung that are required for proper cellular recruitment, migration and localization of the cells that contribute to formation and establishment of the protective granuloma $[25,46]$. In vitro studies show that BMM produce IL-6, TNF- $\alpha$ and IL$1 \beta$ following TDM treatment [25]. These findings emulate the response seen in vivo, where pro-inflammatory cytokine production is strongly upregulated as early as one day after intravenous administration of TDM [16, 33]. Relevant to this study, Welsh et al. [16] demonstrated that cohesiveness of the granulomatous structure is lost when mice are unable to produce IL- 6 , even when TNF- $\alpha$ levels remain sufficiently elevated. This may represent pathophysiologic mechanisms that differ between initiation (TNF- $\alpha$-related) and maintenance (IL-6-related) pathways to control granulomatous pathologies.

The pleiotropic cytokine IL- 6 is produced by several cell types including monocytes, lymphocytes, fibroblasts and endothelial cells [47]. IL-6 contributes to the immune response through multiple mechanisms including upregulation of pro-inflammatory mediators (such as adhesion molecules and acute-phase proteins), hematopoiesis and $\mathrm{T}$ cell differentiation [48-50]. Of specific relevance, IL-6 has been shown to amplify leukocyte recruitment by inducing production of MCP-1 and IL-8 [51], as well as directly aid in cellular migration by $\beta 1$-integrin activation and fibronectin-dependent migration [52]. Systemically, pro-inflammatory production (IL-6, TNF- $\alpha$ and IL-1 $\beta$ ) also activates the HPA axis, resulting in synthesis and release of corticosterone into the bloodstream. However, a conundrum arises when one considers that systemically delivered corticosterone suppresses further production of IL- 6 , TNF- $\alpha$ and IL- $1 \beta$ to the site of inflammation.

Activation of the HPA axis by IL- 6 , TNF- $\alpha$ and IL- $1 \beta$ is an essential protective host response to inflammation [50]. Mice deficient in IL-6 retain the ability to produce corticosterone following challenge by inflammatory 

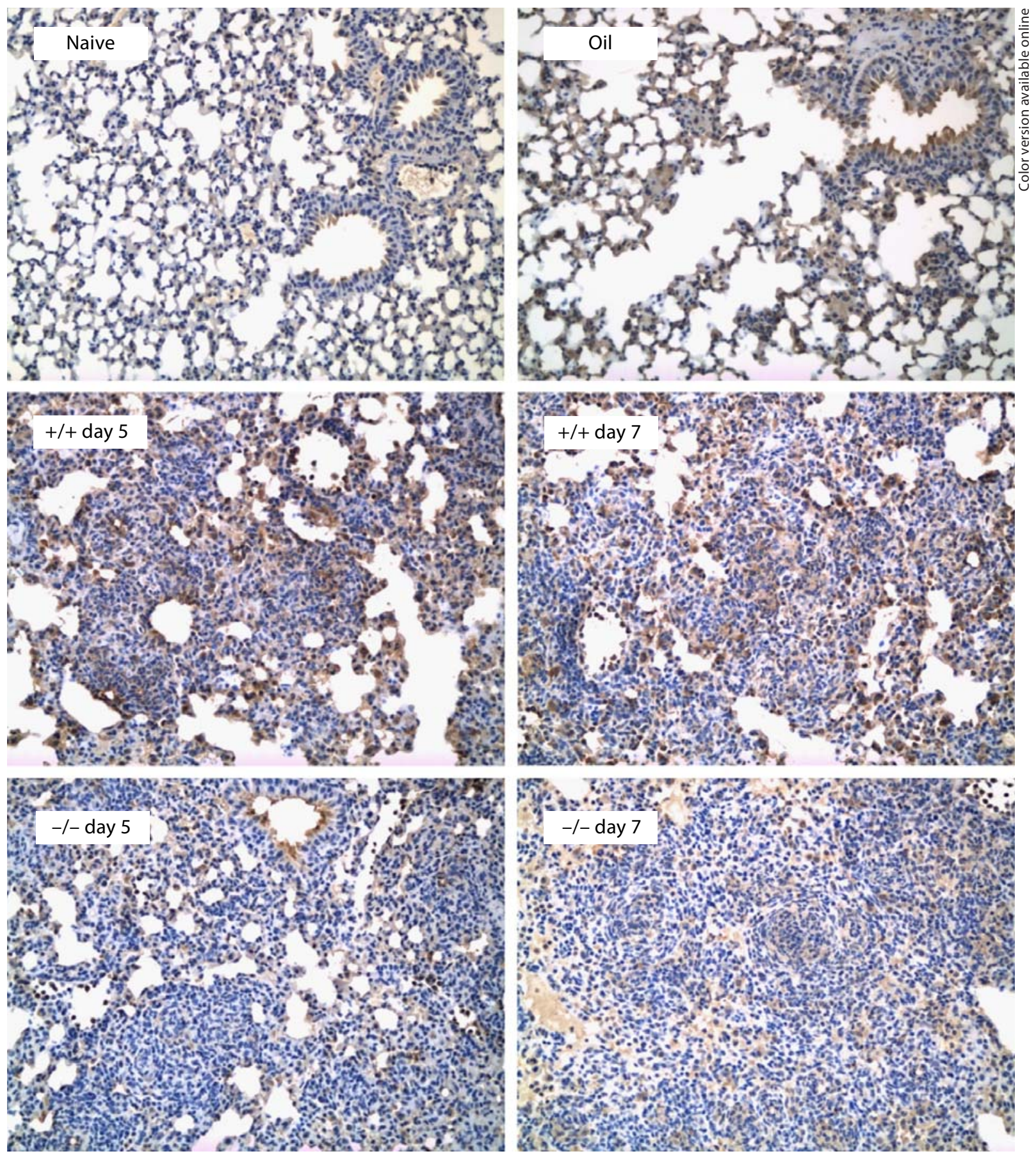

Fig. 7. Increased expression of $11 \beta \mathrm{HSD} 2$ following TDM treatment. Lungs of naive and emulsion-only (oil) treated C57BL/6 mice did not exhibit immunoreactivity against 11ßHSD2 antibodies. Due to the difference in background, only cells with punctate, brown immunoreactivity were considered positive. Immunohistochemical analysis of TDM-treated animals, at day 7 , revealed strong reactivity, particularly in the periphery of granulomatous lesions. Very few positive cells were observed in the lungs of IL-6-/- animals at either day 5 or 7 . Slides treated in parallel, except for addition of $11 \beta \mathrm{HSD} 2$ antibody (control), displayed no positive reactivity. All slides were counterstained with hematoxylin to visualize nuclei. $\times 200$. 
Fig. 8. Lung homogenates spiked with IL- 6 had increased levels of $11 \beta$ HSD2. Lung homogenates were incubated with TNF- $\alpha$ or IL-6, and levels of 11ßHSD1 mRNA (a) or $11 \beta \mathrm{HSD} 2$ mRNA (b) were assessed. Neither TNF- $\alpha$ nor IL- 6 treatment of lung homogenates affected the level of 11ßHSD1 mRNA. IL- 6 at either dose (1 or $5 \mathrm{ng}$ ) resulted in a significant increase of $11 \beta \mathrm{HSD} 2$ mRNA in lung homogenates when compared to the untreated group. TNF- $\alpha$ administration did not significantly alter the type 2 enzyme levels. $n=6 ;{ }^{*} \mathrm{p}<0.05$.

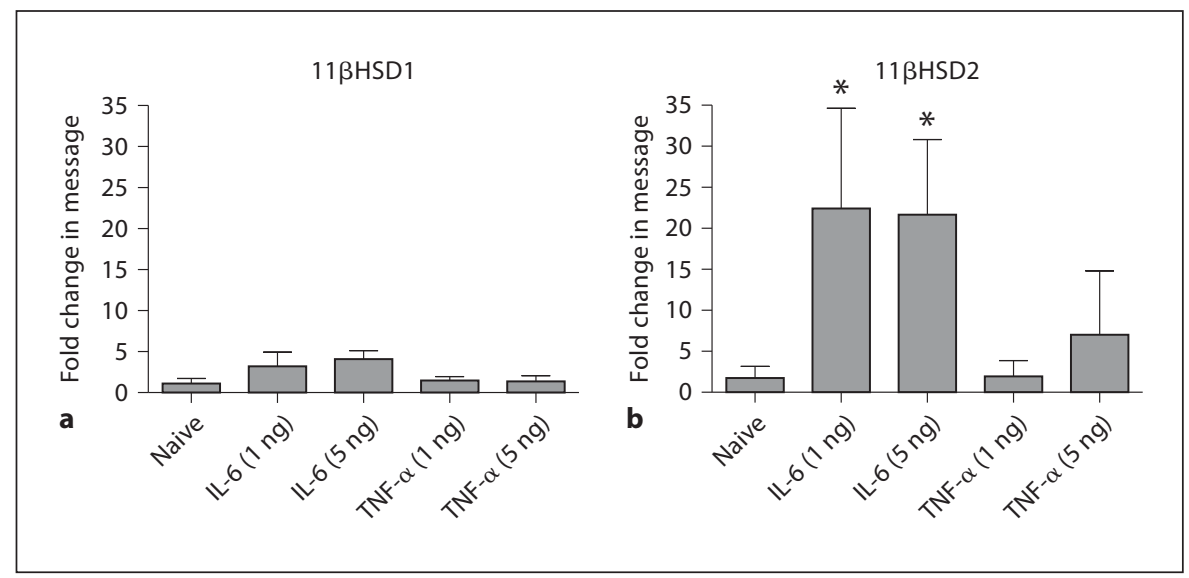

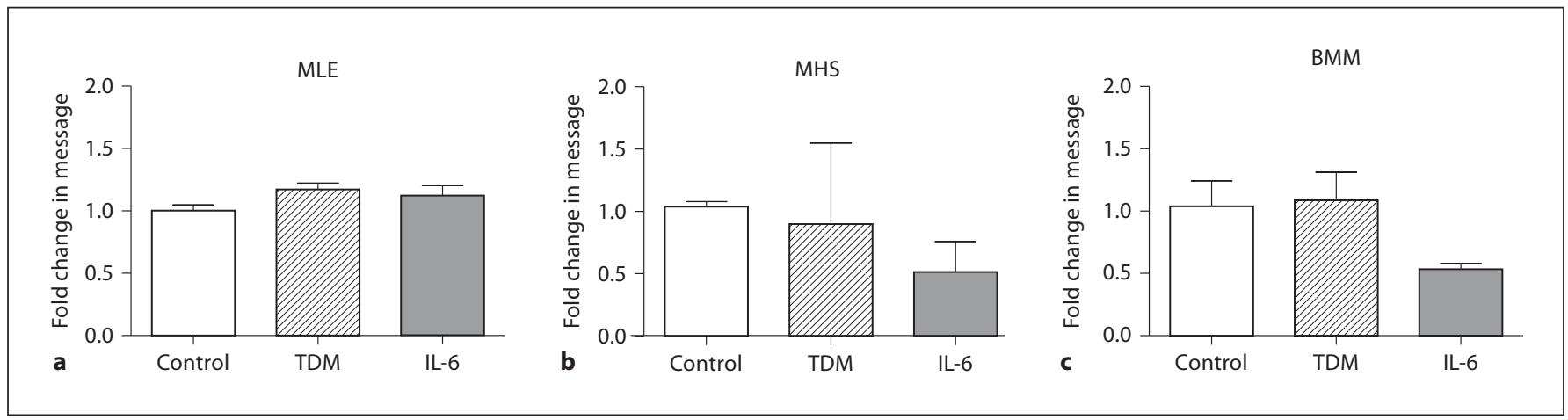

Fig. 9. IL- 6 treatment did not enhance $11 \beta \mathrm{HSD} 2 \mathrm{mRNA}$ levels in individual cell types. IL- 6 and TDM were assessed for potential to induce 11ßHSD2 mRNA from cultured cell lines. Cell lines investigated were a type II epithelial cell line (a; MLE15), an alveolar macrophage cell line (b; MHS), or BMM (c). Each line was incu- bated with IL-6- or TDM-coated beads, however, there was no significant effect on expression of 11ßHSD2 mRNA. Comparisons were made to control BSA-coated beads. $\mathrm{n}=3$ for BMMs; $\mathrm{n}>4$ for MLE15 and MHS cell lines. stimuli [53]. The relative level of HPA activation in IL-6deficient animals most likely depends on the ability of the host to compensate by significantly upregulating production of other pro-inflammatory cytokines and mediators. Although HPA activation determines circulating GC levels, the $11 \beta \mathrm{HSD}$ directly impact cellular exposure to functional corticosterone in the lung, as a site-specific mechanism. Indeed, other investigators have shown sitespecific regulation of the HPA activation in response to pro-inflammatory inducing stimuli [54]. In human TB disease IL-6 (and other cytokines) are elevated [55]. Serum IL-6 levels correlated positively with cortisol $[13,56]$. In the model presented here, pulmonary and serum corticosterone levels were not altered in the IL- 6 knockout mice, however, it is speculated that active GCs are critical in determining pathological outcome. Perhaps this relates to acute stimulation, as seen here, as compared to the long-term responses found in chronic infected individuals. We have shown that pulmonary $11 \beta H S D$ s and corticosterone are modulated in response to TDM in a manner that supports granuloma formation and maintenance. This study addresses enzyme regulation during the dysregulated granulomatous response seen in IL-6deficient mice, specifically linking loss of structural cohesiveness following TDM administration with aberrant induction of pulmonary $11 \beta \mathrm{HSD} 2$.

At the site of inflammation, 11ßHSD2 is produced during granuloma formation and maintenance both in the TDM model and during infection (unpubl. data). The only known function of $11 \beta \mathrm{HSD} 2$ is to reduce local cor- 

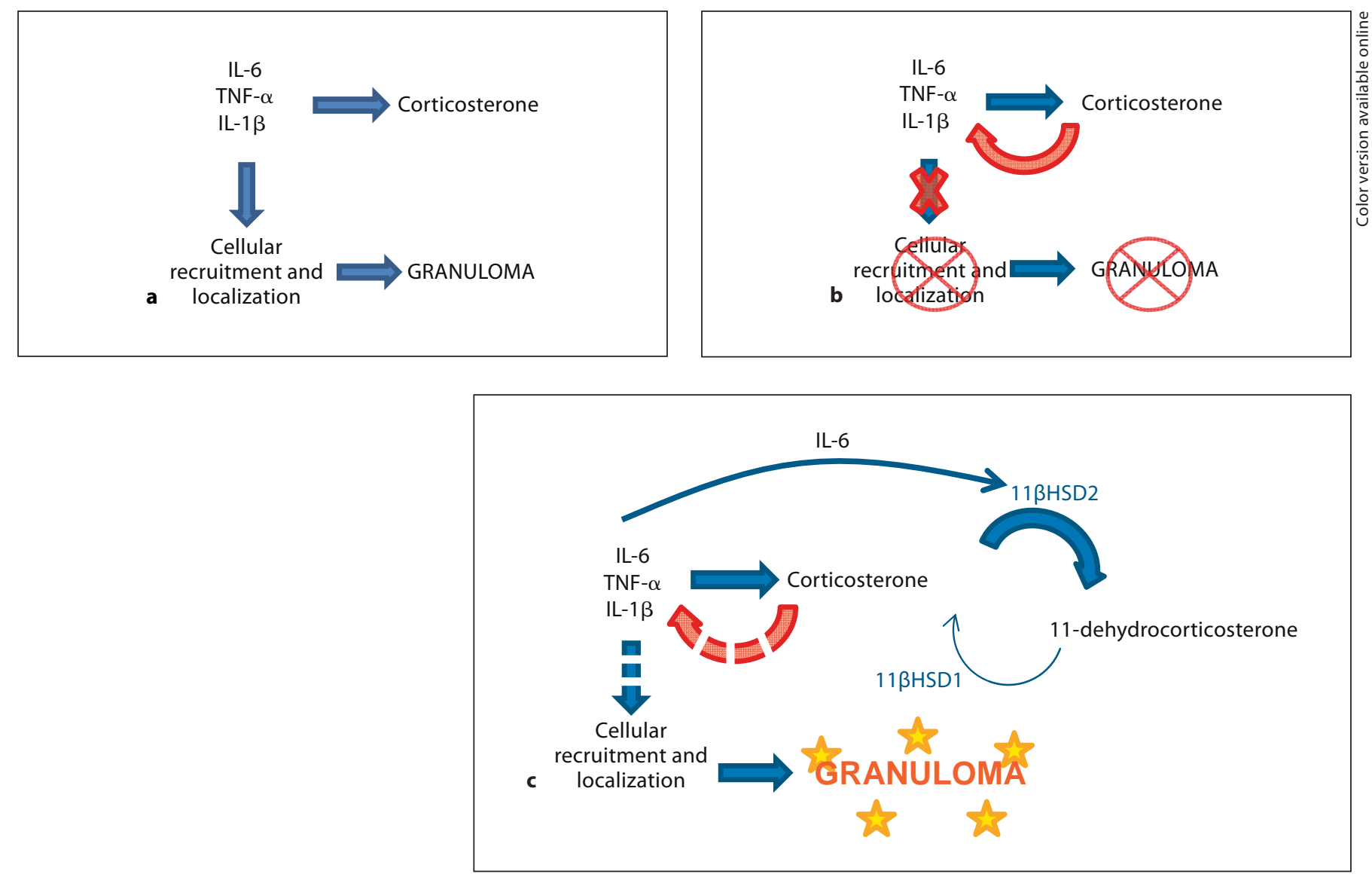

Fig. 10. Regulation of endocrine and immune interactions to promote granuloma formation. The pro-inflammatory cytokines (IL- 6 and TNF- $\alpha$ ) produced in response to TDM have been shown to be essential for the recruitment, migration, localization and adhesion of cells that comprise the granuloma (a). Furthermore, IL- 6 , TNF- $\alpha$ and IL- $1 \beta$ are potent activators of the HPA, resulting in corticosterone production and release. Conversely, corticosterone suppresses production of these inflammatory mediators and is known to elicit breakdown of the granulomatous response (b). Therefore, some mechanism must be in place to regulate corticosterone concentrations at the site of inflammation (c). Evidence that $11 \beta H S D 2$ production is increased while $11 \beta H S D 1$ is decreased as a mechanism to limit lung corticosterone levels has emerged. Furthermore, IL- 6 may directly enhance the shuttling of active corticosterone into inert 11-dehydrocorticosterone at the site of granuloma formation. ticosterone levels; therefore, the modulation of GCs during the granulomatous response is likely of importance to the host. This is supported by work performed by Rook et al. [22], in which a shift towards dehydrogenase activity (that is, conversion of corticosterone to 11-dehydrocorticosterone) was noted in the lungs of mice infected with BCG. The mechanisms by which $11 \beta \mathrm{HSD} 2$ production is regulated are unknown. High doses of GCs have been shown to induce expression of the enzyme in a human bronchial epithelial cell line (BEAS-2B) [57], while TNF- $\alpha$ treatment decreases $11 \beta \mathrm{HSD} 2$ production in these cells [58]. The effect of IL-6 on 11ßHSD2 has not been clearly defined. Lung homogenates treated with a dose of IL-6 that is equivalent to what is encountered during granuloma formation exhibited increased production of $11 \beta H S D 2$ mRNA (approximately 22 -fold). The cell type responsible for the dramatic up-regulation in the type 2 enzyme could not be established. Type II epithelial cells (MLE15) as well as macrophages (BMM and MHS) did not exhibit changes in 11ßHSD2 message following treatment with IL-6. These observations point to the possibility that interaction between certain cell types or factors yet undetermined may play a role in upregulating $11 \beta \mathrm{HSD} 2$ production. Our findings of tissue specificity of response raise additional questions which remain unanswered at this time. Specifically, a drop in 11ßHSD1 
mRNA is seen in liver tissue at 3 days post TDM administration in the sufficient mice. One would hypothesize an increase in these levels, due to high circulating TNF$\alpha ; 11 \beta H S D 1$ mRNA was shown to be upregulated in TNF- $\alpha$ overexpressing mice [59]. Perhaps acute pressures regulate message differently than elevated constitutive factors.

In summary, the inability of IL-6-deficient animals to produce protective granulomatous structures corresponded with aberrant production of $11 \beta H S D 2$. Whether IL-6 directly contributed to breakdown of the response, or whether IL-6 deficiency affects 11ßHSD2 expression and thereby exposes the microenvironment to elevated levels of active GCs needs to be addressed. Identifying the factors that contribute to maintenance of granulomas may provide great insight into novel therapeutics approaches to enhance the ability of the host to fight myco- bacterial infections [60]. Furthermore, the only known motivation for this phenomenon is to limit the concentration of active GCs in the lung. This finding provides significant insight into host protective mechanisms that can possibly be exploited therapeutically to aid in generating the protective granulomatous response.

\section{Acknowledgements}

The authors would like to thank Dr. Greg Shipley of the Quantitative Genomics Core Laboratory at UTHSC for technical help with RNA studies and quantitative analysis of changes in message levels. This work was completed in partial fulfillment of requirements for the PhD degree from the University of Texas Graduate School of Biomedical Sciences at Houston, program in Molecular Pathology.

\section{References}

1 World Health Organization, Global tuberculosis control: WHO report 2010. Geneva. World Health Organization, 2010.

$\checkmark 2$ Dye C, et al: Measuring tuberculosis burden, trends, and the impact of control programmes. Lancet Infect Dis 2008;8:233-243.

-3 Flynn JL, et al: Tumor necrosis factor-alpha is required in the protective immune response against Mycobacterium tuberculosis in mice. Immunity 1995;2:561-572.

4 Actor JK, et al: Relationship of survival, organism containment, and granuloma formation in acute murine tuberculosis. J Interferon Cytokine Res 1999;19:1183-1193.

5 Russell DG: Who puts the tubercle in tuberculosis? Nat Rev Microbiol 2007;5:39-47.

6 Ulrichs T, Kaufmann SH: New insights into the function of granulomas in human tuberculosis. J Pathol 2006;208:261-269.

7 Egen JG; et al: Macrophage and T cell dynamics during the development and disintegration of mycobacterial granulomas. Immunity 2008:28:271-284.

-8 Russell DG, Barry CE 3rd, Flynn JL: Tuberculosis: what we don't know can, and does, hurt us. Science 2010;328:852-856.

-9 Calcagni E, Elenkov I: Stress system activity, innate and Thelper cytokines, and susceptibility to immune-related diseases. Ann NY Acad Sci 2006;1069:62-76.

10 Webster JI, Sternberg EM: Role of the hypothalamic-pituitary-adrenal axis, glucocorticoids and glucocorticoid receptors in toxic sequelae of exposure to bacterial and viral products. J Endocrinol 2004;181:207-221.

11 Bottasso O, et al: The immuno-endocrine component in the pathogenesis of tuberculosis. Scand J Immunol 2007;66:166-175.
12 Bottasso O, et al: Immunoendocrine alterations during human tuberculosis as an integrated view of disease pathology. Neuroimmunomodulation 2009;16:68-77.

13 Mahuad C, et al: Impaired immune responses in tuberculosis patients are related to weight loss that coexists with an immunoendocrine imbalance. Neuroimmunomodulation 2007;14:193-199.

14 Barnes PJ: How corticosteroids control inflammation: Quintiles Prize Lecture 2005. Br J Pharmacol 2006;148:245-254.

$\checkmark 15$ Algood HM, Lin PL, Flynn JL: Tumor necrosis factor and chemokine interactions in the formation and maintenance of granulomas in tuberculosis. Clin Infect Dis, 2005;41(suppl 3):S189-S193.

16 Welsh KJ, et al: A role for tumour necrosis factor-alpha, complement C5 and interleukin- 6 in the initiation and development of the mycobacterial cord factor trehalose 6,6'-dimycolate induced granulomatous response. Microbiology 2008;154:1813-1824.

17 Chakravarty SD, et al: Tumor necrosis factor blockade in chronic murine tuberculosis enhances granulomatous inflammation and disorganizes granulomas in the lungs. Infect Immun 2008;76:916-926.

-18 Saunders BM, et al: Interleukin-6 induces early gamma interferon production in the infected lung but is not required for generation of specific immunity to Mycobacterium tuberculosis infection. Infect Immun 2000; 68:3322-3326.

19 Tait AS, Butts CL, Sternberg EM: The role of glucocorticoids and progestins in inflammatory, autoimmune, and infectious disease. J Leukoc Biol 2008;84:924-931.
20 Hernandez-Pando R, et al: Emergent immunoregulatory properties of combined glucocorticoid and anti-glucocorticoid steroids in a model of tuberculosis. QJMed 1998;91: 755-766.

21 Howard AD, Zwilling BS: Reactivation of tuberculosis is associated with a shift from type 1 to type 2 cytokines. Clin Exp Immunol 1999:115:428-434.

22 Rook G, et al: Local regulation of glucocorticoid activity in sites of inflammation. Insights from the study of tuberculosis. Ann NY Acad Sci 2000;917:913-922.

23 Yamagami H, etal:Trehalose 6,6'-dimycolate (cord factor) of Mycobacterium tuberculosis induces foreign-body- and hypersensitivitytype granulomas in mice. Infect Immun 2001;69:810-815.

24 Behling CA, et al: Induction of pulmonary granulomas, macrophage procoagulant activity, and tumor necrosis factor-alpha by trehalose glycolipids. Ann Clin Lab Sci 1993; 23:256-266.

25 Perez RL, et al: Cytokine message and protein expression during lung granuloma formation and resolution induced by the mycobacterial cord factor trehalose-6,6'dimycolate. J Interferon Cytokine Res 2000; 20:795-804.

26 Actor JK, et al: Mycobacterial glycolipid cord factor trehalose 6,6'-dimycolate causes a decrease in serum cortisol during the granulomatous response. Neuroimmunomodulation 2002;10:270-282.

27 Ozeki Y, et al: In vivo induction of apoptosis in the thymus by administration of mycobacterial cord factor (trehalose 6,6'-dimycolate). Infect Immun 1997;65:1793-1799. 
-28 Actor JK, et al: Cytokine mRNA expression and serum cortisol evaluation during murine lung inflammation induced by $\mathrm{Myco}$ bacterium tuberculosis. Comb Chem High Throughput Screen 2000;3:343-351.

-29 Draper N, Stewart PM: 11beta-hydroxysteroid dehydrogenase and the pre-receptor regulation of corticosteroid hormone action. J Endocrinol 2005;186:251-271.

-30 Abbott AN, et al: 11beta-hydroxysteroid dehydrogenases are regulated during the pulmonary granulomatous response to the mycobacterial glycolipid trehalose-6,6'-dimycolate. Neuroimmunomodulation 2009; 16:147-154

-31 Guidry TV, et al: Failure of CD1D-/- mice to elicit hypersensitive granulomas to mycobacterial cord factor trehalose 6,6'dimycolate. J Interferon Cytokine Res 2004; 24:362-371.

-32 Chi V, Chandy GK: Immunohistochemistry: paraffin sections using the Vectastain $A B C$ kit from Vector Labs. J Vis Exp 2007;8:308.

-33 Abbott AN, et al: 11ß-hydroxysteroid dehydrogenases are regulated during the pulmonary granulomatous response to the mycobacterial glycolipid trehalose- $6,6^{\prime}$ dimycolate. Neuroimmunomodulation 2009;16:147-154.

\$34 Livak KJ, Schmittgen TD: Analysis of relative gene expression data using real-time quantitative PCR and the $2^{-\Delta \Delta \mathrm{C}_{\mathrm{T}}}$ method. Methods 2001;25:402-408.

-35 Guidry TV, Hunter RL Jr, Actor JK: CD3+ cells transfer the hypersensitive granulomatous response to mycobacterial glycolipid trehalose 6,6'-dimycolate in mice. Microbiology 2006;152:3765-3775.

>36 Indrigo J, Hunter RL Jr, Actor JK: Influence of trehalose $6,6^{\prime}$-dimycolate (TDM) during mycobacterial infection of bone marrow macrophages. Microbiology 2002;148:19911998.

>37 Indrigo J, Hunter RL Jr, Actor JK: Cord factor trehalose 6,6'-dimycolate (TDM) mediates trafficking events during mycobacterial infection of murine macrophages. Microbiology 2003;149:2049-2059.
38 SecklJR, Walker BR: 11 $\beta$-hydroxysteroid dehydrogenase type 1 as a modulator of glucocorticoid action: from metabolism to memory. Trends Endocrinol Metab 2004;15:418424.

39 Rook GA, Hernandez-Pando R: Pathogenetic role, in human and murine tuberculosis, of changes in the peripheral metabolism of glucocorticoids and antiglucocorticoids. Psychoneuroendocrinology 1997;22(suppl 1):S109-S113.

40 Rook GA, Hernandez-Pando R: The pathogenesis of tuberculosis. Annu Rev Microbiol 1996;50:259-284.

41 Hernandez-Pando R, et al: The effects of androstenediol and dehydroepiandrosterone on the course and cytokine profile of tuberculosis in BALB/c mice. Immunology 1998 95:234-241.

42 Paige C, Bishai WR: Penitentiary or penthouse condo: the tuberculous granuloma from the microbe's point of view. Cell Microbiol 2010;12:301-309.

43 Tsai MC, et al: Characterization of the tuberculous granuloma in murine and human lungs: cellular composition and relative tissue oxygen tension. Cell Microbiol 2006;8 218-232.

44 Rhoades ER, Frank AA, OrmeI M: Progression of chronic pulmonary tuberculosis in mice aerogenically infected with virulent Mycobacterium tuberculosis. Tuber Lung Dis 1997;78:57-66.

45 Ladel CH, et al: Lethal tuberculosis in interleukin-6-deficient mutant mice. Infect Immun 1997;65:4843-4849.

46 Perez RL, et al: Extravascular coagulation and fibrinolysis in murine lung inflammation induced by the mycobacterial cord factor trehalose-6,6'-dimycolate. Am J Respir Crit Care Med 1994;149:510-518

47 Van Snick J: Interleukin-6: an overview. Annu Rev Immunol 1990;8:253-278.

48 Ishihara K, HiranoT: IL-6 in autoimmune disease and chronic inflammatory proliferative disease. Cytokine Growth Factor Rev, 2002;13:357-368.

49 Dienz O, Rincon M: The effects of IL-6 on CD4 T cell responses. Clin Immunol 2009; 130:27-33.
50 Elenkov IJ, et al: Cytokine dysregulation, inflammation and well-being. Neuroimmunomodulation 2005;12:255-269.

51 Romano M, et al: Role of IL- 6 and its soluble receptor in induction of chemokines and leukocyte recruitment. Immunity 1997;6: 315-325.

52 Clahsen T, Schaper F: Interleukin-6 acts in the fashion of a classical chemokine on monocytic cells by inducing integrin activation, cell adhesion, actin polymerization, chemotaxis, and transmigration. J Leukoc Biol 2008;84:1521-1529.

53 Fattori E, et al: Defective inflammatory response in interleukin 6-deficient mice. J Exp Med 1994;180:1243-1250.

54 Turnbull AV, et al: Interleukin-6 is an afferent signal to the hypothalamo-pituitary-adrenal axis during local inflammation in mice. Endocrinology 2003;144:1894-1906.

55 Rey $\mathrm{AD}$, et al: Endocrine and cytokine responses in humans with pulmonary tuberculosis. Brain Behav Immun 2007;21:171179.

56 Bottasso O, Morales-Montor J: Neuroimmunomodulation during infectious diseases: mechanisms, causes and consequences for the host. Neuroimmunomodulation 2009; 16:65-67.

57 Suzuki S, et al: Dexamethasone upregulates $11 \beta$-hydroxysteroid dehydrogenase type 2 in BEAS-2B cells. Am J Respir Crit Care Med 2003;167:1244-1249.

58 Suzuki S, et al: Inflammatory mediators down-regulate $11 \beta$-hydroxysteroid dehydrogenase type 2 in a human lung epithelial cell line BEAS-2B and the rat lung. Tohoku J Exp Med 2005;207:293-301.

59 Ignatova ID, et al: Tumor necrosis factor- $\alpha$ upregulates $11 \beta$-hydroxysteroid dehydrogenase type 1 expression by CCAAT/enhancer binding protein- $\beta$ in HepG2 cells. Am J Physiol Endocrinol Metab 2009;296:E367E377.

60 Rook GA, Baker R, Zumla A: Steroid metabolism and immunity: therapeutic implications. BioDrugs 1997;8:157-163. 